\title{
MICRODISC GEL ELECTROPHORESIS IN SODIUM DODECYL SULFATE OF ORGANIC MATERIAL FROM RAT OTOCONIAL COMPLEXES*
}

\author{
M. D. Ross, K. G. Pote, K. E. Rarey, and L. M. Verma \\ Department of Anatomy \\ University of Michigan \\ Ann Arbor, Michigan 48109
}

\section{INTRODUCTION}

The gravity receptors of all vertebrates utilize a "test mass" consisting of a complex arrangement of mineral and organic substance that lies over the sensory receptor areas (maculas). ${ }^{23}$ Carlström has shown that in most vertebrates, the mineral is a polymorph of calcium carbonate (vaterite, aragonite, calcite) in the form of minute, single crystals called otoconia ("ear dust"), ${ }^{2}$ The otoconia contain a small amount of organic material that is continuous with intervening and underlying organic substance of the otoconial membrane, the organic and inorganic complements being referred to here collectively as an otoconial complex. In contrast, in certain fishes, a solitary otolith ("ear stone") occurs or mixtures of otoliths and otoconia are present. ${ }^{2}$ The Agnatha, which otherwise lack mineralized tissue, have otoconia that, surprisingly, contain calcium phosphate (amorphous apatite, Reference 2).

In the gravity receptors of man and other warm-blooded animals, only calcite is present and the otoconia have a basically similar morphology regardless of the species studied (FIGURES 1-3). They exhibit the characteristic threefold symmetry of calcite, and the rhombohedron is the basic structural unit. Moreover, the mammalian otoconia have the crystallographic properties of single crystals of calcite including the appropriate Miller indices (1011) (determined for human otoconia, see Reference 16). ${ }^{2.16}$ Thus, the otoconia of man and other mammals take their shape largely from the mineral they contain rather than from their organic fractions (FIGURE 4), even though both materials may be essential to their existence.

It is unclear why individual crystals of mineral substance occur in an overwhelming number of vertebrate inner ears when other mineral deposits in the body are polycrystalline, or why one polymorph of calcium carbonate is used preferentially instead of another in particular classes of animals. From a chemical viewpoint, however, the fact that calcium ions combine with anions to form a mineral deposit in all normal vertebrate inner ears implies that phylogenetically there was a need to store calcium against periods of short supply. The fact that a well-ordered array of mineral material and organic substance has endured throughout the long evolutionary history of the vertebrate gravity receptors demonstrates that perfection of function was approached by this union. Required ions were stored in their ground-energy state (or entatic state) ${ }^{21}$ through the participation of an appropriate "capture" protein material (see Reference 24). The end result was a reservoir of ions to buffer the surrounding fluid

*This work was conducted with the support of National Aeronautics and Space Administration Grant NSG 9047 and National Institutes of Health Grant AG00767. 
(endolymph) against periods of calcium ion deficiency and against shifts in pH while, simultaneously, providing needed mass to make the detection of the direction of gravitational force easier.

This viewpoint of otoconial complexes leads naturally to the question of the chemical nature of the organic material that is found within and outside of the otoconial crystals. Organic substance appears to be essential to calcite seeding and crystal growth of otoconia in the fetus and to the rapid accumulation of calcium ions observed under certain in vivo and in vitro experimental conditions. ${ }^{12,14,17-19,22}$ New calcite cannot form with the rapidity encountered in these experiments under purely inorganic mechanisms of crystal growth.

Organic substance also apparently protects otoconia against dissolution. Mathematical calculations of coefficients of activities of the ions in artificial endolymph (and perilymph) used in in vitro studies have demonstrated that pure calcite would have dissolved in the fluids, but otoconia did not. ${ }^{17}$ Little is known with certainty about the chemical nature of the organic material inside and outside otoconia (the material at the two sites may not be identical), except that it is PAS-positive $f$ and that it is, or contains, glycoprotein. ${ }^{25}$

Detailed chemical analysis of the organic substance would appear to be a formidable task. A pair of saccular complexes of the rat weighs only about $9.5 \mu \mathrm{g}$, and a pair of utricular complexes about $14.5 \mu \mathrm{g} .{ }^{18}$ As much of this mass consists of the heavier calcite, it would seem at first glance that the amount of organic material would be too small to allow meaningful analyses, even through heroic efforts of pooling of samples. However, new and extremely sensitive microanalytical methods for separating proteins out of mixtures according to their molecular weights are appearing constantly in the literature, and ever more exquisitely sensitive amino acid analyzers are coming on the market. Thus, analysis of at least the protein constituents of otoconial organic substance appears possible.

In this article we describe some of the results of our efforts to determine the number of proteins in otoconial complexes and their molecular weights using a microdisc gel electrophoresis method presented by Gainer. ${ }^{6}$ Although we began this research by pooling 60 complexes per sample, we have learned that pooling of only 4 to 10 complexes is necessary for a single analysis, and the prospect of analyzing a sample consisting of only one pair of saccular or utricular complexes is bright. The work is, nevertheless, complicated in that several technical modifications, solubility tests, and staining procedures should be employed before results can be considered to be definitive and the proteins can be said to be well characterized. Early indications are, however, that the proteins of saccular and of utricular complexes are identical and that one of the major proteins has a relatively low molecular weight, $\sim 17,000$ daltons. This is within the range of molecular weights of other known calcium-binding proteins, such as calmodulin and troponin-C. The exciting possibility exists that this peptide will prove to be the calcium-fixing protein in otoconial complexes.

\section{MATERIAL AND METHODS}

Sprague-Dawley rats were used throughout. Except for initial studies in which large numbers of otoconial complexes were pooled (up to 60) from discard rats of various weights, animals 250-325 g have been used. The method of protein separation we have employed routinely is microdisc gel electrophoresis and 


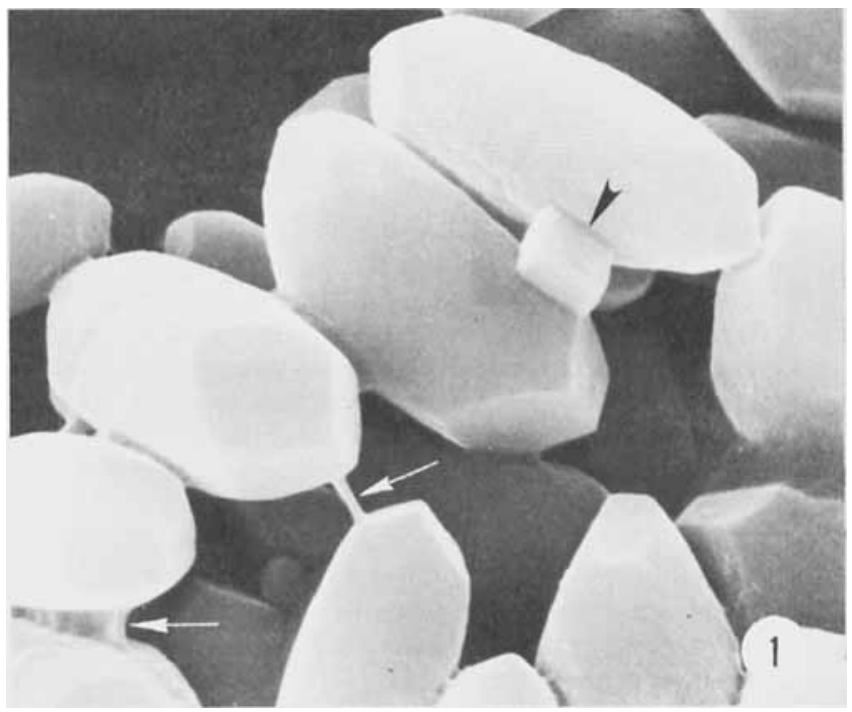

FIGURE 1. Human utricular otoconia have a configuration typical of mammals (compare with FIGUREs 2 and 3]. The majority of the otoconia have rounded body surfaces and pointed ends. The three terminal faces are typical of calcite crystals (see FIGURE 4). Organic material is present in the otoconia (not seen) and is continuous with organic substance intervening between the crystals (arrows). A few otoconia in the rhombohedral form occur in human utricular complexes (arrowhead, upper right). $\times 6,630$.

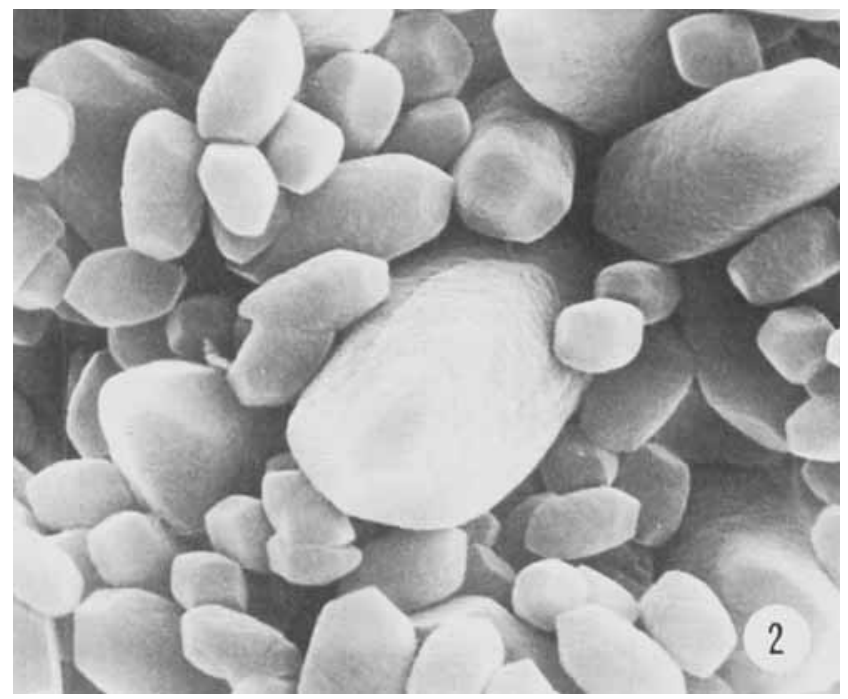

FIGURE 2. Otoconia typical of the monkey utricle are illustrated. Compare with Figures 1,3 , and $4 . \times 5,100$. 


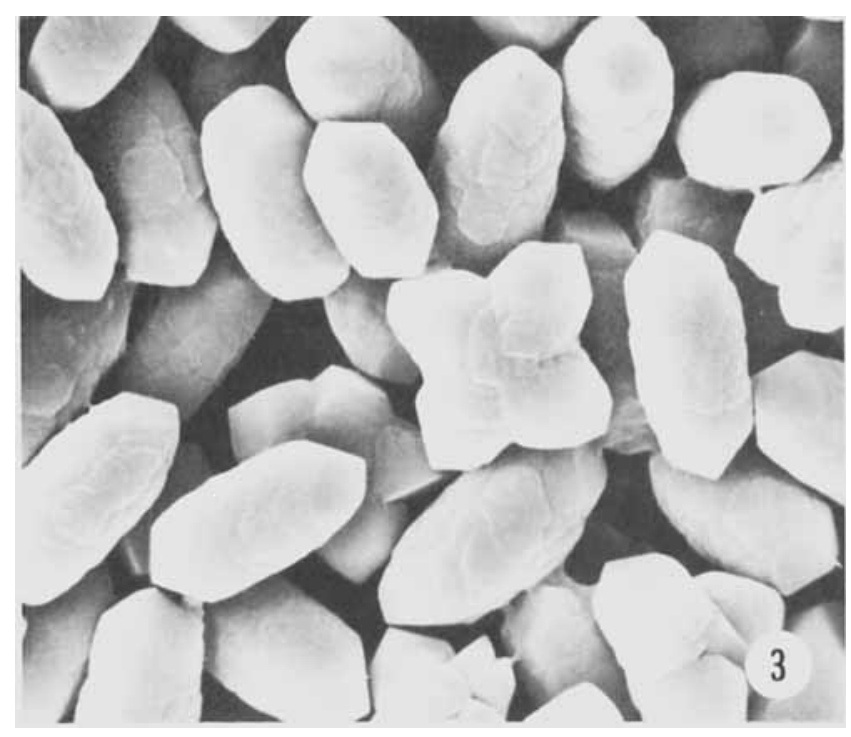

FIGURE 3. Rat saccular otoconia have slightly more irregular body surfaces than do either monkey or human otoconia, but the basic configuration is the same. Crossed otoconia like the one near the center of the electron micrograph are found in other species and may be a form of crystal twinning. $\times 2,550$.

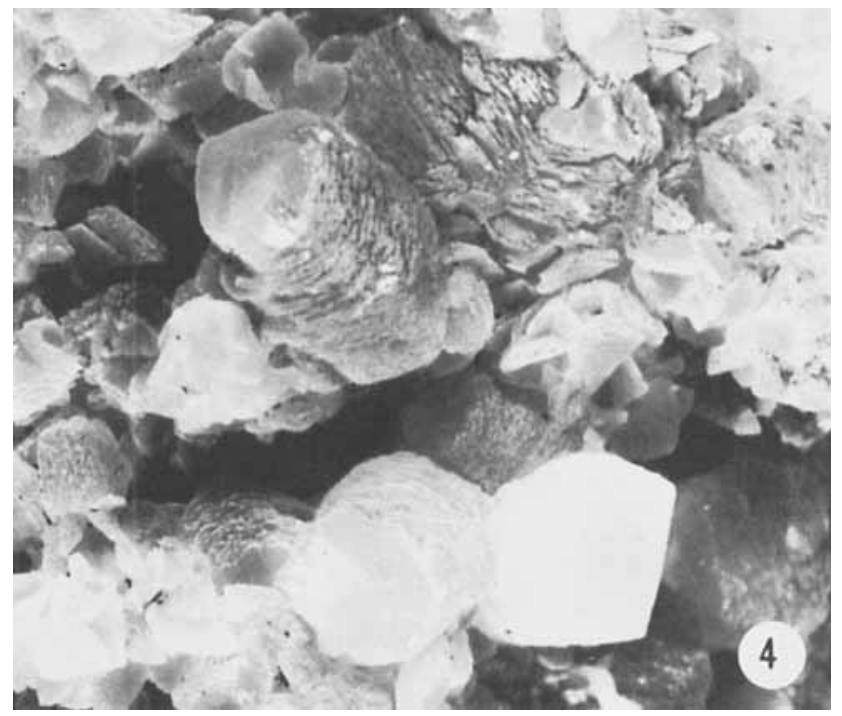

FIGURE 4. Inorganic calcite sometimes has a configuration similar to that of otoconia, as this photomicrograph demonstrates. This specimen is from a collection at the Department of Geology and Mineralogy, University of Michigan, origin unknown. $\times 2.21$. 
Coomassie blue staining of the gels as described by Gainer. ${ }^{6}$ This method is capable of detecting $5 \times 10^{-10} \mathrm{~g}$ protein.

\section{Microdissection and Sample Collection}

Animals were decapitated, and the bullas were removed quickly to small dishes for microdissection. Initially, microdissections of otoconial complexes were carried out in distilled water (double distilled, deionized) under the assumption that the organic material of the otoconial membrane most likely was insoluble in water. However, all recent experiments have been carried out in artificial endolymph (AE) to better match ionic conditions normally present around the tissues being dissected and to minimize cell lysis and protein contamination of our samples. Artificial endolymph was prepared according to the following formula. ${ }^{15,1}$

\section{AE: $1.0 \mathrm{mM} \mathrm{NaCl} ; 148 \mathrm{mM} \mathrm{KCl} ; 10 \mathrm{mM} \mathrm{KHCO}_{3}$; \\ $1 \mathrm{mM} \mathrm{MgCl}_{2} ; 1.5 \mathrm{mM} \mathrm{CaCl}_{2}, \mathrm{pH} 7.4-7.8$}

The tissue was removed to fresh fluid several times as the otoconial complexes were dissected rapidly, and the complexes always were moved to fresh fluid immediately before they were picked up with the aid of a micropipette. This served to wash away possible contaminating proteins. The sample then was placed in a 1.5-ml centrifuge tube with $\sim 3 \mu l$ of fluid. Saccular and utricular complexes were kept separate. Otoconial complexes from 2-6 animals were pooled, and the supernatant fluid was removed carefully. Otoconial samples were utilized immediately or were stored (covered) at $-42^{\circ} \mathrm{C}$ until used.

\section{EDTA Chelation}

Our early work was carried out by collecting 30-60 otoconial samples in small foil cups to which a drop or two of $0.1 \mathrm{M}$ (ethylenedinitrilo)-tetraacetic acid (EDTA) was added. The cups were supported in wells in staining dishes, and chelation was carried out in the cold. The EDTA was withdrawn carefully every other day, and after a week, when it appeared that only a gel-like residue was left, the samples were dried over silica gel. The residue was solubilized in sodium dodecyl sulfate [SDS) and prepared for gel electrophoresis. This method led to some variation in results, and therefore direct solubilization in SDS was attempted (see below). EDTA also has been used in combination with trichloroacetic acid (TCA) for comparison with non-EDTA-treated material, to examine the question of solubility of some otoconial complex protein in EDTA.

\section{Solubilization and Denaturation}

Two different methods of denaturation and solubilization have proved successful.

1. The first of these involved direct solubilization and denaturation of the pooled complexes in a mixture of $3 \mu \mathrm{I}$ SDS and $3 \mu \mathrm{I} \beta$-mercaptoethanol in an oven at $100^{\circ} \mathrm{C}$ for three-five minutes. The mixture next was cooled and then doubled with $2 \times$ concentrated upper buffer, which contained dithiothreitol and bromo- 
phenol blue. Approximately 6 microliters of this fluid served as the sample that was placed on the gel. When saccular and utricular samples were combined for comparison purposes, $\sim 3 \mu \mathrm{l}$ of each sample were combined (6 $\mu$ l total) for analysis.

2. The second method was more complicated, and some sample loss may have occurred because of the washes involved. Otoconial complexes were dissolved in TCA at $90^{\circ} \mathrm{C}$ for 15 minutes. The residue was cooled on ice for 5 minutes and then centrifuged in a cold room (Eppindorf centrifuge, $\sim 15,000 \mathrm{~g}$ force) for about 45 minutes. The supernatant was withdrawn carefully, and the residue was washed twice in cold acetone, with the supernatant carefully wicked away. After the last wash, the residual acetone was evaporated in an oven at $37^{\circ} \mathrm{C}$. This left a very small, whitish mass [assumedly protein], which then was solubilized in SDS at $90^{\circ} \mathrm{C}$ for 5 minutes. The solution was cooled to room temperature, and $\beta$-mercaptoethanol was added according to Gainer's recipe. After the volume was doubled with $2 \times$ concentrated upper buffer, procedures outlined under method 1 were followed.

\section{Gels}

The gels were made according to the recipe provided by Gainer except for addition of $0.1 \%$ SDS. ${ }^{6}$ The stacking gel in initial studies was $3 \%$ polyacrylamide ( $\mathrm{pH}$ 6.1), and the running gel was $7.5 \%$ (pH 9.2). In order to achieve better separation of some of our bands, we recently have used a $3.0 \%$ (pH 6.1) stacking gel and a $12.5 \%$ (pH 9.2) running gel. The gels were cast in hematocrit tubes $7 \mathrm{~cm}$ long and having a uniform internal bore of $1.1 \mathrm{~mm}$.

\section{Conditions of Electrophoresis and Staining}

Upper and lower buffers have been prepared following Gainer's methodology. In order to sharpen our bands, we added $1 \mathrm{mM}$ ethyleneglycol-bis( $\beta$-aminoethyl ether] $N, N^{\prime}$-tetraacetic acid (EGTA) to the upper buffer (the EGTA chelates any calcium ions present). The $7.5 \%$ gels were run at constant voltage $(120 \mathrm{~V})$ at $5 \mathrm{~mA}[0.5 \mathrm{~mA} / \mathrm{gel})$ in a Model 1400 Ames gel bath with a Miles RP500 power supply. The $12.5 \%$ gels were run with a constant current of $0.5 \mathrm{~mA} / \mathrm{gel}$, with voltage between 120 and 450 .

Routinely, the electrophoresis was continued until the bromophenol blue reached within $1 \mathrm{~cm}$ of the bottom of the gels; but on some occasions the electrophoresis was stopped when the tracking dye had traveled only about halfway down the gels. This was done to determine whether one or more peptides were running ahead of the dye. The gels were removed from the tubes and placed in test tubes with $0.25 \%$ Coomassie blue stain for 2-16 hours. The gels were destained in a solution of acetic acid and methanol, as described by Gainer.

\section{Standards}

Standards were run simultaneously with the unknowns (otoconial complex samples] to make molecular-weight determinations possible. We have employed 
Dalton Mark VI, bovine hemoglobin, chymotrypsinogen, $\beta$-galactosidase, and lysozome (obtained from Sigma Chemical Co., St. Louis, Mo., USA].

\section{Molecular-Weight Determination}

The gels were read on a Quantimet 720 image-analyzing computer using a software computer program written for the purpose by Thomas J. Williams. Relative mobility of each protein peak was calculated as

$$
\begin{aligned}
\text { Relative mobility }= & \left(\frac{\text { distance of protein migration }}{\text { length of the running gel after destaining }}\right) \\
& \times\left(\frac{\text { length of the running gel before destaining }}{\text { distance of bromophenol blue migration }}\right)
\end{aligned}
$$

A standard curve was obtained by plotting the relative mobilities of the standard proteins against the log of their molecular weights. The molecular weights of the unknown sample proteins were extrapolated from this standard curve.

\section{Scanning Electron Microscopy}

Otoconial complexes were exposed to artificial endolymph for 15 or 30 minutes, removed, coated with gold, and examined in a JEOL JSM U-3 scanning electron microscope at $15 \mathrm{kV}$. This was done to determine the effect (if any) of the fluid on otoconial complex integrity and to ascertain the relative cleanness of the samples we were analyzing.

\section{RESULTS}

The initial electrophoretic results obtained with residues derived through chelation of otoconial complexes prior to solubilization and denaturation in SDS- $\beta$-mercaptoethanol were encouraging because bands of protein separated out on the gels and their molecular weights could be assessed on the basis of the weights of the standards run simultaneously. The range of molecular weights of the bands produced usually was similar $(\sim 15,000$ to $\sim 55,000$ daltons $)$ from one experiment to another, but the number of bands often was different. These experiments indicated either that the chelation process had some unknown effect on the proteins or that [more likely) withdrawal of the supernatant fluid, which was changed periodically, resulted in loss of soluble proteins.

Direct solubilization in SDS yielded more promising results. Two major protein bands were evident in both saccular and utricular complexes by this method. The lower-molecular-weight material was in the range of $16,800-18,000$ daltons, and the higher-molecular-weight protein was $\sim 51,000$ daltons. Several minor bands were present in between the major bands but often were not identical from one trial to the next. During the period when these experiments were conducted, using the combination of $3 \%$ and $7.5 \%$ gels, we learned that as few as four pooled complexes provided sufficient protein to serve as samples for two gels. We also began to carry out microdissections in artificial endolymph, and scanning electron microscopy of otoconial complexes prepared in this fluid 
demonstrated that the complexes were in superior condition even after one-half hour or more exposure to the fluid (FIGURE 5). Such periods of time are far in excess of those required for microdissection of our samples (5-10 minutes).

In order to determine if low-molecular-weight peptides were running ahead of the bromophenol blue, the electrophoresis sometimes was terminated when the dye had reached the midpoint of the gels. Subsequent staining of the gels failed to demonstrate the presence of bands below the tracking dye.

The matter of variability in minor protein bands observed from one experiment to the next had to be resolved. We therefore attempted to obtain a more pure protein sample by employing the TCA method of protein precipitation. The precipitate produced always was exceedingly small and was lost completely on

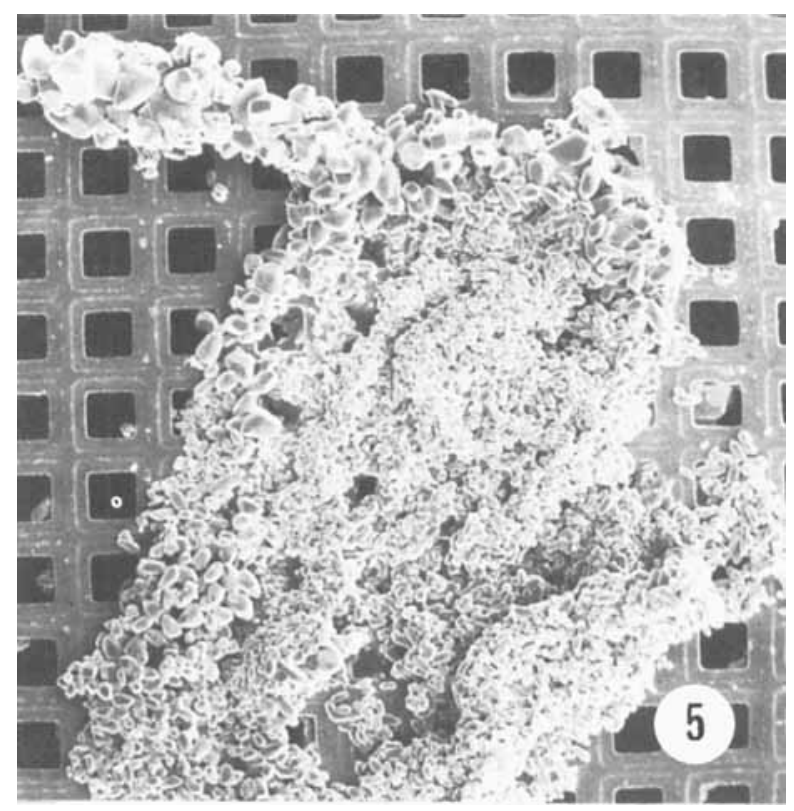

FIGURE 5. The typical appearance of a utricular otoconial complex microdissected in artificial endolymph is demonstrated here. The sample is free of debris, and otoconial integrity has been maintained. This complex was exposed to artificial endolymph for 30 minutes, but collection of the sample ordinarily requires only $5-10$ minutes. $\times 100$.

more than one occasion during the washing procedures when the sample inadvertently was wicked away with the acetone wash. Nevertheless, several experiments were successful and provided further evidence that there were two major proteins in the organic substance in the saccular and utricular complexes. The proteins apparently were identical, for the two kinds of complexes and their molecular weights corresponded in general to those observed in our previous experiments. Minor bands still differed in number and in molecular weight from one experiment to the next. The problem of possible loss of some protein during the TCA preparative procedures became worrisome.

In order to avoid this possibility, direct solubilization and denaturation in SDS and $\beta$-mercaptoethanol were reinstated. In addition, the running gel concentra- 
tion was increased to $12.5 \%$. This was done to slow the migration of the lower-molecular-weight peptides. The results of experiments run under these conditions were consistent from one day to the next. The bands were sharply defined in the gels, and the pattern of banding appeared to be identical for both major and minor bands of the complexes (FIGURE 6).

Several major protein bands were apparent in gels run under these improved experimental conditions. Two of the most prominent occurred at $\sim 16,500$ and

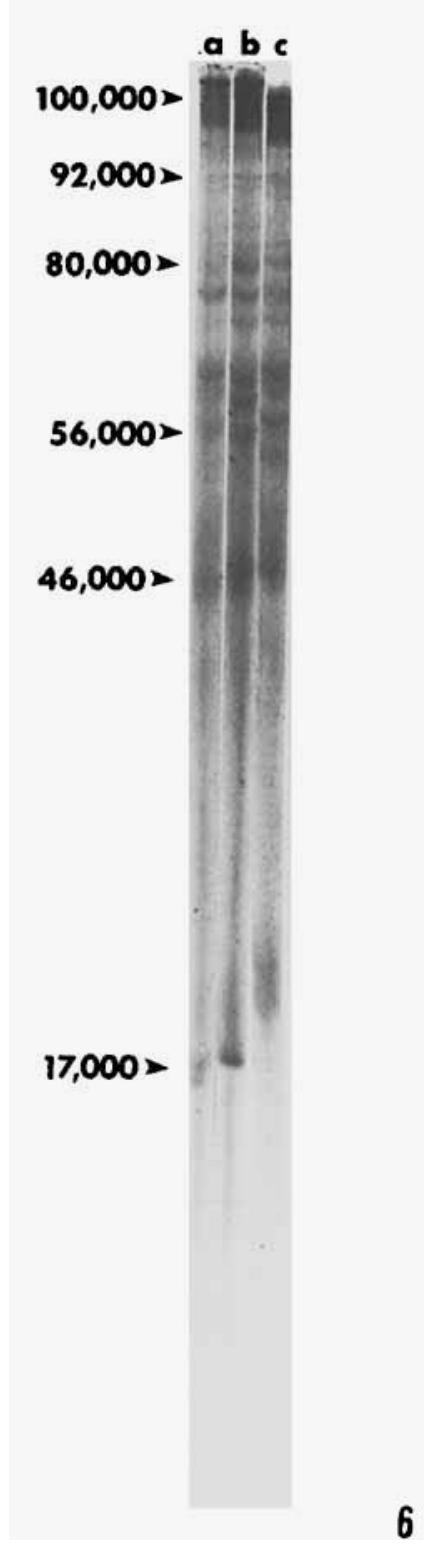

FIGURE 6. A typical set of $12.5 \%$ gels containing proteins obtained from saccular (a), combined saccular and utricular (b), and utricular (c) complexes is illustrated here. The apparent molecular weights are indicated to the left of the figure and are the same for each sample, based on calculations of the relative mobilities of the proteins compared to standards, with the distance of the bands from the tracking dye taken into account. 
$\sim 46,000$ daltons, and further significant proteins were at $\sim 56,000, \sim 80,000$, and $>100,000$ molecular weight (MW). Several minor bands were present between 56,000 and 80,000 daltons. It was noteworthy that the protein banding pattern of the combined utricular and saccular proteins was identical to the patterns observed in either single sample (FIGURE 6).

\section{Discussion}

The most important finding of this research is that analysis of the proteins of the organic material of the otoconial complexes is possible when sensitive microanalytical methods are employed. The present research has taken only the first step in this direction, but further modification of the basic technique used here and inclusion of other sensitive staining methods should mean that, in the future, protein separation by molecular weight will be possible in sample pools containing only two otoconial masses. This would make the analysis of norma] and defective or nonmineralized human otoconial complexes practical, permitting us to ascertain whether one or more proteins are missing in abnormal complexes.

On the basis of our present results, it appears that the proteins present in saccular and utricular otoconial complexes are identical. This is a matter of some importance to determine, because previous investigations have shown that saccular otoconia are more prone than the utricular to degenerate with age and disease, or after administration of certain drugs. ${ }^{7-9.11,16}$ It was demonstrated also that in vivo uptake and/or exchange of ${ }^{45} \mathrm{Ca}^{++}$occurs more rapidly and in greater quantities in saccular otoconia. ${ }^{18}$ These findings could indicate that some inherent chemical and structural difference existed between otoconia from the two sites, but our results indicate that some other explanation must be sought.

It is of interest that a major protein band in the range of $\sim 17,000$ daltons separated out consistently in the gels. This apparent molecular weight is within the range of other known calcium-fixing proteins. For example, the MW of calmodulin has been reported to be $\sim 15,000-19,000$ daltons under various experimental conditions, and $16,790 \mathrm{MW}$ by amino acid sequencing. ${ }^{10}$ Troponin$\mathrm{C}$ has a calculated $\mathrm{MW}$ of 17,846 and has been reported to weigh between $\sim 17,000$ and 22,000 when differing analytical methods were employed. ${ }^{3}$ It is possible that the low-molecular-weight protein we have identified in otoconial complexes is an analogous calcium-binding agent, especially in light of the fact that the calcium-fixing proteins show remarkable stability in evolution with respect to their amino acid content and sequencing.

In this same context it is relevant to note that Degens and his colleagues found that the protein of fish otolith. which they named otolin, is a highly acidic, fibrous protein with a molecular weight of $>150,000 .^{4,5}$ Cleavage with urea/hydroxylamine produced units of $\sim 70,000-80,000 \mathrm{MW}$. Fish otoliths contain the aragonite polymorph of calcium carbonate. In the case of mollusc shells containing the calcite polymorph, cleavage with hydroxylamine yielded proteins ranging between 20,000 and $\mathbf{8 0 , 0 0 0}$ daltons. ${ }^{4}$ The range in otoconial complex protein material is $\sim 17,000$ to $>100,000$. Further tests and the use of additional standard will be required to define the upper limit of the high-molecular-weight proteins present. It is worthwhile emphasizing, however, that the molecular weights of the proteins of fish otoliths, mollusc shells, and otoconial complexes, insofar as these have been determined, are more alike than dissimilar even though different methods of protein analysis were used. The extent of agreement is remarkable considering that the biosystems investigated had little more in common than their 
ability to store a polymorph of calcium carbonate. On the other hand, the organic material of the otoconial complexes seems to be entirely different from that of a related inner ear membrane, the tectorial. Steel carried out SDS gel electrophoresis of the tectorial membranes of normal and abnormal mice and found in both cases] a range of $\sim 62,000-180,000 \mathrm{MW}$, with a major band at 140,000 daltons. $^{20}$

It is important to note that Degens reported that water-soluble proteins account for between 0.1 and $2 \%$ of the total organic material in shells. Meenakshi et al. discussed their own findings as well as those of other investigators, which indicate that it is the intracrystalline part of shell protein that is particularly water- and EDTA-soluble. ${ }^{13}$ Thus, pretreatment with EDTA, such as we carried out in our first experiments, is to be avoided unless the purpose is to analyze the fluid for soluble proteins. We have not yet fully characterized the EDTA-soluble [or water-soluble] protein[s) of otoconial complexes.

The reliability of the findings we have made in these initial studies will depend upon the cleanness of the samples we have analyzed. Scanning electron microscopy of some of the samples that we have microdissected demonstrates that our specimens are free of debris (Figure 5]. It is impossible to know that every sample is equally clean, however. The reproducibility of protein banding from one experiment to another under our improved experimental conditions leads us to believe that contamination is not a significant factor in our results. However, further experiments in which otoconia are separated from otoconial membrane material by centrifugation or sedimentation procedures, then washed and analyzed, will be required before this question can be answered entirely.

\section{ACKNOWLEDGMENTS}

We thank Dr. Babu Vadlamudi and Mr. Charles Daniels of the Department of Biological Chemistry for their technical assistance during this research, and Dr. Dale Oxender of the Department of Biological Chemistry for use of equipment essential to the investigation.

\section{REFERENCES}

1. BOSHER, S. K. \& R. L. WARREN. 1978. Very low calcium content of cochlear endolymph, an extracellular fluid. Nature 273: 377-378.

2. Carlström, D. 1963. A crystallographic study of vertebrate otoliths. Biol, Bull. 125: 441-463.

3. Collins, J. H., J. D. POTTER, M. J. Horn, G. Wilshire \& N. Jackman. 1973. The amino acid sequence of rabbit skeletal muscle troponin-C: gene replication and homology with calcium-binding proteins from carp and hake muscle. FEBS Lett. 36: 268-272.

4. Degens, E. T. 1976. Molecular mechanisms on carbonate, phosphate, and silica deposition in the living cell. Top. Curr. Chem. 64: 1-112.

5. Degens, E. T., W. G. Deuser \& R. L. Haedrich. 1969. Molecular structure and composition of fish otoliths. Marine Biol. 2: 105-113.

6. GAINER, H. 1971. Micro disc electrophoresis in sodium dodecyl sulfate. An application to the study of protein synthesis in individual identified neurons. Anal. Biochem. 44: 589-605.

7. HARADA, Y. \& Y. SUGIOMOTO. 1977. Metabolic disorder of otoconia after streptomycin intoxication. Acta Otolaryngol. 84: 65-71.

8. JOHNSSON, L.-G. 1971. Degenerative changes and anomalies of the vestibular system in man. Laryngoscope 81: 1682-1694. 
9. JOHNSSON, L.-G. \& J. E. HAwKINS, JR. 1972. Sensory and neural degeneration with aging, as seen in microdissections of the human inner ear. Ann. Otol. 81: 179-193.

10. KleE, C. B., T. H. Crouch \& P. G. Richman. 1980. Calmodulin. Ann. Rev. Biochem. 49: 489-515.

11. LIM, D. J. 1973. Formation and fate of the otoconia. Ann. Otol. Rhinol. Laryngol. 82: $23-35$.

12. LYON, M. F. 1955. The development of the otoliths of the mouse. J. Embryol. Exp. Morphol. 3: 213-229.

13. Mennakshi, V. T., P. E. HARE \& K. M. Wilbur. 1971. Amino acids of the organic matrix of neogastropod shells. Comp. Biochem. Physiol. 40B: 1037-1043.

14. Nakahara, H. \& G. Bevelander. 1979. An electron microscope study of crystal calcium carbonate formation in the mouse otolith. Anat. Rec. 193: 233-241.

15. RauCH, S. 1964. Biochemie des Hörorgans. Georg Thieme Verlag. Stuttgart, Federal Republic of Germany.

16. Ross, M. D., L.-G. Johnsson, D. Peacor \& L. Allard. 1976. Observations on normal and degenerating human otoconia. Ann. Otol. 85: 310-326.

17. Ross, M. D., K. G. POTE, P. L. Cloke \& C. CORSON. 1980. In vitro ${ }^{45} \mathrm{Ca}^{++}$uptake and exchange by otoconial complexes in high and low $\mathrm{K}^{+} / \mathrm{Na}^{+}$fluids. The Physiologist 23: S129-S130.

18. Ross, M. D. \& T. J. Williams. 1979. Otoconial complexes as ion reservoirs in endolymph. The Physiologist 22: S63-S64.

19. Salamat, M. S., M. D. Ross \& D. R. PEacor. 1980. Otoconial formation in the fetal rat. Ann. Otol. 89: 229-238.

20. STEEL, K. 1980. The proteins of normal and abnormal tectorial membranes. Acta Otolaryngol. 89: 27-32.

21. Vallee, B. L. \& R. J. P. Williams. 1968. Metalloenzymes: the entatic nature of their active sites. Proc. Nat. Acad. Sci. 59: 498-505.

22. VeENHOF, V. B. 1969. The development of statoconia in mice. Thesis. University of Amsterdam. Amsterdam, the Netherlands.

23. VINNIKOV, YA. A. 1974. Evolution of the gravity receptor. Minerva Otorinolaringol. 24: 1-48.

24. Williams, R. I. P. 1979. Inorganic elements in biology and medicine. Chem. Br. 15: 506-512.

25. Wislocki, G. B. \& A. J. LADMAN. 1955. Selective and histochemical staining of the otolithic membranes, cupulae and tectorial membrane of the inner ear. J. Anat. 89: 3-12. 